\title{
Transmission of Xylella fastidiosa to Grapevine by the Meadow Spittlebug
}

\author{
D. Cornara, A. Sicard, A. R. Zeilinger, F. Porcelli, A. H. Purcell, and R. P. P. Almeida
}

First and fourth authors: DiSSPA, sez. Zoologia ed Entomologia, Università degli Studi di Bari Aldo Moro, via Amendola 165/A, 70126 Bari; and second, third, fifth, and sixth authors: ESPM, University of California-Berkeley, 130 Mulford Hall 3114, Berkeley, CA 94720. Accepted for publication 30 June 2016.

\begin{abstract}
Cornara, D., Sicard, A., Zeilinger, A. R., Porcelli, F., Purcell, A. H., and Almeida, R. P. P. 2016. Transmission of Xylella fastidiosa to grapevine by the meadow spittlebug. Phytopathology 106:1285-1290.

There is little information available on Xylella fastidiosa transmission by spittlebugs (Hemiptera, Cercopoidea). This group of insect vectors may be of epidemiological relevance in certain diseases, so it is important to better understand the basic parameters of $X$. fastidiosa transmission by spittlebugs. We used grapevines as a host plant and the aphrophorid Philaenus spumarius as a vector to estimate the effect of plant access time on $X$. fastidiosa transmission to plants; in addition, bacterial population estimates in the heads of vectors were determined and correlated with plant infection status. Results show that transmission efficiency of $X$. fastidiosa

by $P$. spumarius increased with plant access time, similarly to insect vectors in another family (Hemiptera, Cicadellidae). Furthermore, a positive correlation between pathogen populations in $P$. spumarius and transmission to plants was observed. Bacterial populations in insects were one to two orders of magnitude lower than those observed in leafhopper vectors, and population size peaked within 3 days of plant access period. These results suggest that $P$. spumarius has either a limited number of sites in the foregut that may be colonized, or that fluid dynamics in the mouthparts of these insects is different from that in leafhoppers. Altogether our results indicate that $X$. fastidios $a$ transmission by spittlebugs is similar to that by leafhoppers. In addition, the relationship between cell numbers in vectors and plant infection may have under-appreciated consequences to pathogen spread.
\end{abstract}

The bacterium Xylella fastidiosa is an economically important plant pathogen that is present throughout the Americas, Europe (Italy and France), Asia (Taiwan), and the Middle-East (Almeida and Nunney 2015). The lifestyle of $X$. fastidiosa requires the colonization of insect and plant hosts; in addition, natural dispersal is solely mediated by insect vectors (Chatterjee et al. 2008). Therefore, knowledge about insect and plant colonization, as well as plant-to-plant transmission can guide the development of control strategies for diseases caused by $X$. fastidiosa. Traditionally, research has focused on how this pathogen colonizes host plants, with some but more limited attention given to insect hosts. In addition, some of the key parameters of X. fastidiosa vector transmission have been determined.

Insect vectors belong to three groups of xylem sap-feeding insects, the sharpshooter leafhoppers (Hemiptera: Cicadellidae Cicadellinae), spittlebugs (Hemiptera: Cercopoidea), and cicadas (Hemiptera: Cicadoidaea). There are only two reports of cicadas as vectors (Krell et al. 2007; Paião et al. 2002), and because of the limited information more research is required on the role of these insects in $X$. fastidiosa spread. The first identified $X$. fastidiosa vectors were sharpshooter leafhoppers (Hewitt and Houston 1946; Hewitt et al. 1942). Frazier and Freitag (1946) demonstrated that several leafhopper species transmitted $X$. fastidiosa, information which decades later led Frazier (1965) to propose that xylem sap feeding insects should be considered vectors of this pathogen until proven otherwise; this proposal still stands (Almeida and Nunney 2015). The superfamily Cercopoidea has five families, Aphrophoridae, Cercopidae, Clastopteridae, Epigydae, and Machaerotidae. Epigyds have, to our knowledge, not been studied as insect vectors

Corresponding author: R. Almeida; E-mail address: rodrigoalmeida@berkeley.edu

*The $\boldsymbol{e}$-Xtra logo stands for "electronic extra" and indicates that one supplementary table is published online.

http://dx.doi.org/10.1094/PHYTO-05-16-0202-R

(C) 2016 The American Phytopathological Society of plant pathogens. Machaerotids are tube-building insects that have not been shown to transmit $X$. fastidiosa but are vectors of Ralstonia syzygii, a xylem-colonizer that causes Sumatra disease of clove trees (Eden-Green et al. 1992). Insects in the other three families have been shown to transmit $X$. fastidiosa. Severin (1950) demonstrated that three aphrophorids (Philaenus spumarius [syn. Philaenus leucophthalmus], Aphrophora angulata, and Aphrophora permutata) and one clastopterid (Clastoptera brunnea) were vectors of X. fastidiosa. Purcell (1980) and Saponari et al. (2014) also confirmed that $P$. spumarius was a vector of this bacterium to plants. In addition, Clastoptera achatina (Clastopteridae) and Lepyronia quadrangularis (Aphrophoridae) were shown to transmit $X$. fastidiosa to pecans (Sanderlin and Melanson 2010). Severin (1950) referred to $P$. spumarius as P. leucophtalmus; he also stated that five varieties of the meadow spittlebugs were tested (leucophtalmus, pallidus, fabricii, marginellus, and impressus). In 1961, the Commission of Zoological Nomenclature decided that the valid specific name for this taxon was spumarius and not leucophtalmus; the polymorphism and variation of wing markings generated confusion in the nomenclature (Yurtsever 2000).

Severin (1950), however, was the only study to provide information on the characteristics of transmission other than vector identification. In that study it was shown that $P$. spumarius transmission of $X$. fastidiosa lacked a detectable latent period (shortest period tested of $2 \mathrm{~h}$ ) and that the bacterium was persistently retained in adults (up to 76 days). The transmission of $X$. fastidiosa to plants by sharpshooter leafhoppers has similar characteristics; it lacks a latent period (Purcell and Finlay 1979) and is persistent in adults (Almeida and Purcell 2003b; Hill and Purcell 1995a). Additional work with leafhoppers has shown that $X$. fastidiosa is not transovarially (Freitag 1951) or transtadially transmitted (Almeida and Purcell 2003b; Purcell and Finlay 1979). The lack of latent period, transovarial, and transtadial transmission, suggest that the retention site of $X$. fastidios $a$ is in the foregut of leafhopper vectors, which was first shown using microscopy by Purcell et al. (1979). Recent work by Cornara et al. (2016) also documented $X$. fastidiosa-like cells in the foregut of the aphrophorid $P$. spumarius. The observed lack of $X$. fastidiosa genotype-vector 
species specificity among leafhoppers has not been analyzed for spittlebugs, but these insects transmit $X$. fastidiosa strains belonging to at least three different subspecies (Sanderlin and Melanson 2010; Saponari et al. 2014; Severin 1950), suggesting that this is also a conserved trait. Despite the lack of research on the Cercopoidea as vectors of $X$. fastidios $a$, the limited information available suggests that parameters of plant-to-plant transmission are similar to those described for sharpshooter leafhoppers.

Two important parameters affecting the spread of $X$. fastidiosa diseases, however, are pathogen transmission efficiency (over time) and rate (one time point), both of which vary based on host plant-insect-pathogen combinations (Lopes et al. 2009; Purcell 1981). Transmission can also be affected by within plant feeding preferences by insect vectors (Daugherty et al. 2010) or vector discrimination against disease symptomatic plant tissue (Zeilinger and Daugherty 2014). There are no data on spittlebug- $X$. fastidiosa transmission efficiency (i.e., how the frequency of transmission events changes over time). In addition, the diagnostic and quantification of $X$. fastidiosa cells in the foregut of insect vectors has been challenging to perform until the more recent advent of molecular diagnostic tools for this purpose. Currently available data based on cell culturing estimates (Almeida and Purcell 2003b; Hill and Purcell 1995a) suggest no relationship between size of $X$. fastidiosa populations in vectors and transmission to plants; in other words, a larger cell population does not seem to lead to more infection events, which is intriguing as $X$. fastidiosa microcolonies grow in population size over time within the foregut of vectors (Almeida and Purcell 2006; Killiny and Almeida 2009b). In addition, undetectable $X$. fastidiosa populations are sufficient for transmission (Hill and Purcell 1995a). We performed studies to determine $X$. fastidiosa transmission efficiency by $P$. spumarius on grapevines, and used qPCR to identify infected individuals as well as to estimate $X$. fastidiosa population size in vectors.

\section{MATERIALS AND METHODS}

Insect collection and rearing. Philaenus spumarius nymphs were field collected at an organic olive orchard in Marin County, $\mathrm{CA}$, with no record of $X$. fastidiosa (based on plant samples that were taken from this site over the duration of this project, in addition the site had no history of $X$. fastidiosa presence). Morphological identification of insects followed Ossiannilsson (1981). Main hosts from which insects were collected were bristly oxtongue (Helminthotheca echioides), common vetch (Vicia sativa), California barley (Hordeum brachyantherum), and wild oats (Avena fatua), in March to April 2015. Nymphs were transferred using a 3-mm-wide brush to vetch, fava bean (Vicia faba), parsley (Petroselinum crispum), or basil (Ocimum basilicum), in groups of 25 individuals caged with mesh fabric cages in a greenhouse insectary (average temperature day/night $23.5^{\circ} \mathrm{C}$, recorded every $30 \mathrm{~min}$ by a data logger) until adults emerged. Adults were pooled in groups of 30 individuals and transferred to vetch plants, with plants replaced every 10 days. Adult $P$. spumarius mortality exceeded $50 \%$ under greenhouse conditions during the summer. All spittlebugs were prescreened for the presence of $X$. fastidiosa by caging groups of 10 individuals per plant on 3-month-old Cabernet Sauvignon seedlings for 4 days (Almeida and Purcell 2003b). Insects were then transferred to vetch plants until used. Pretest plants were kept in a greenhouse (average temperature day/night $25.6^{\circ} \mathrm{C}$ ), watered daily, and observed weekly for possible disease symptoms. Four months after the inoculation access period (IAP), the pretest plants were tested for X. fastidiosa by culturing on PWG (Hill and Purcell 1995a). No pretest plants were infected with $X$. fastidiosa; 18 of 444 spittlebugs died during the 4-day pretest period.

Pathogen and grapevine plants. We used the $X$. fastidiosa subspecies fastidiosa STL strain (Almeida and Purcell 2003b) for all experiments. To generate pathogen source plants, 2-monthold Vitis vinifera 'Cabernet Sauvignon' grapevine seedlings were needle inoculated (Almeida and Purcell 2003a). Every plant was inoculated at 5 and $20 \mathrm{~cm}$ from the base with a 5- $\mu$ ldrop of a $10^{9}$ $\mathrm{CFU} / \mathrm{ml}$ suspension (population assessed by dilution plating) in sodium-citrate-phosphate (SCP) buffer with a number 1 entomological pin. Plants were watered daily and fertilized once every month (Osmocote Plus 15-9-12). Source plants were tested for $X$. fastidiosa by culturing 1 month after inoculation, then pruned to $20 \mathrm{~cm}$ in height. One month after pruning, X. fastidiosa population in the distal third of the plants was determined by culturing; plants with petiole samples with 3 to $6 \times 10^{6} \mathrm{CFU} / \mathrm{ml}$ (Hill and Purcell 1997) and $30 \mathrm{~cm}$ tall were used as source plants. Three-month-old cuttings of $V$. vinifera Cabernet Sauvignon grown in 3 galloncapacity pots in a mix of Supersoil, sand, and perlite (2:1:1), watered daily, and fertilized monthly (Osmocote Plus 15-9-12), were used as recipient plants. We pruned the cuttings to $20 \mathrm{~cm}$ height, also removing lateral shoots, 1 week prior to insect access.

Transmission efficiency. We tested how $X$. fastidiosa transmission efficiency by $P$. spumarius on grapevines varied in relation to durations of acquisition access period (AAP) and IAP. Five AAP and IAP treatments were used: $1.5 ; 4.5 ; 12 ; 24$; and $48 \mathrm{~h}$, each with 30 independent replicates, keeping for each treatment a constant IAP of 2 days for variable AAPs, and a 2-day AAP for variable IAPs. Each replicate consisted of one adult individual and one test plant. To minimize the time before the onset of feeding on plants, insects were starved for $1 \mathrm{~h}$ prior to the AAP. Groups of $P$. spumarius adults were caged on three $X$. fastidios $a$ source plants, 15 spittlebugs per plant, with a total of 45 insects per treatment (taking into account possible deaths during the AAP). After the AAP (variable or fixed), 10 individuals from each source plant were randomly selected, transferred to grapevine seedlings, and confined on plants within $10 \mathrm{~cm}$ diameter and $25 \mathrm{~cm}$ tall plastic and cloth cages for the IAP, with access to the entire plant. The design was selected due to practical limitations related to insect and plant handling in limited amounts of time, and to provide insects with ample host plant tissue to select from during acquisition. Diagnostic of test plants was performed two months post inoculation following Hill and Purcell (1995a). After IAP, insects were collected and stored at $-80^{\circ} \mathrm{C}$, and tested for the presence and number of $X$. fastidiosa cells in heads as described below. Plants were treated biweekly with pesticides as necessary and kept in greenhouse with a constant temperature of $28^{\circ} \mathrm{C}$ (Feil and Purcell 2001). A total of 10 out of 270 insects tested died during these assays.

Assessment of vetch as $\boldsymbol{X}$. fastidiosa host. We assessed $V$. sativa as host of $X$. fastidiosa because this plant was suitable for $P$. spumarius rearing in the greenhouse, and Freitag (1951) found that Vicia monarcha was a X. fastidiosa host. Adult $P$. spumarius collected in Anderson Valley, Mendocino Co., CA, where previous collections of the sharpshooter leafhopper Graphocephala atropunctata have never tested positive for X. fastidiosa and Pierce's disease has never been reported (A. H. Purcell, unpublished data), were reared on vetch and prescreened as described above. No pretest plants were infected with $X$. fastidiosa. For the transmission tests, insects were caged for 1 week on three $X$. fastidiosa-infected grapevine source plants in groups of 15 individuals per plant. $P$. spumarius were then starved for $1 \mathrm{~h}$, and then transferred individually to 3120 -day-old $V$. sativa seedlings for an IAP of 3 days. Plants were tested for the presence and populations of $X$. fastidiosa by culturing on PWG medium 1 week after the end of IAP (Hill and Purcell 1995a).

P. spumarius natural infectivity. A small survey was performed to determine if naturally infected $P$. spumarius could be found in vineyards; we selected a drip-irrigated vineyard on Spring Mountain in Napa County, CA, because of its record of Pierce's disease and $P$. spumarius presence. In 2015, we followed X. fastidiosa populations in seven symptomatic grapevines of cultivar Merlot and three of cultivar Malbec identified the previous year as being infected with the bacterium. Twice in June, once in July, and once in August, we collected the oldest available basal leaves ( $n=3$ to 5$)$ on a cane and 
estimated $X$. fastidiosa bacterial populations using the culturing method (Hill and Purcell 1995a). We collected P. spumarius by sweeping individuals separately from weeds and from grapevines in the same plot once a month in June, July, and August. P. spumarius were then pooled in groups, keeping separately those collected from grapevines from those collected from weeds. Insects were then caged onto grapevine seedlings, for an IAP of 4 days. At the end of IAP, we preserved the insects in $75 \%$ ethanol for morphological identification, according to Ossiannilsson (1981). Recipient plants were kept in an insect-proof greenhouse and tested 3 months after the IAP by culturing (Hill and Purcell 1995a).

qPCR. A qPCR standard curve was generated according to Daugherty et al. (2009). Briefly, DNA from suspensions of $X$. fastidiosa cultured cells used to correlate the starting number of cells with DNA content was extracted using the Qiagen DNeasy blood and tissue kit (Hilden, Germany) with the pretreatment for gram-negative bacteria following the manufacturer's instructions. In parallel, these suspensions were 10-fold serial diluted on PWG plates. Total DNA from P. spumarius (heads only) was extracted according to Francis et al. (2006) with a final DNA resuspension in $100 \mu$ of $0.5 \times$ TE. Absolute DNA quantifications $\left(40\right.$ cycles of $95^{\circ} \mathrm{C}$ for $10 \mathrm{~s}, 63^{\circ} \mathrm{C}$ for $15 \mathrm{~s}$ and $72^{\circ} \mathrm{C}$ for $30 \mathrm{~s}$ ) were carried out using the GoTaq qPCR Master Mix (Promega) on a 7500 Fast Real-Time PCR thermocycler (Applied Biosystems, Foster City, CA) following the manufacturer's instructions. A reference dye (CXR) was added to each reaction $(0.2 \mu \mathrm{l}) ; 4 \mu \mathrm{l}$ of each sample was added in a $20 \mu \mathrm{l}$ final reaction, each sample run in duplicates. The primers HL5 and HL6, designed by Francis et al. (2006), were used at a final concentration of $0.2 \mu \mathrm{M}$.

Statistical analysis. First, we tested for the relationship between test plant infection status (response variable) and $X$. fastidiosa population in vectors (PCR-positive and PCR-negative individuals), AAP, and IAP (explanatory variables) using mixed-effect logistic regression, with source plant treated as a random effect. Second, we investigated the relationship between populations of $X$. fastidiosa in P. spumarius and time after the beginning of the AAP (AAP plus IAP) using two models. We compared fits of a linear model and Michaelis-Menten (M-M) model: $y=a x /(b+x)$, where $a$ and $b$ are model coefficients, $y$ represents $X$. fastidios $a$ population in spittlebugs estimates, and $x$ represents time after the beginning of the AAP. In both the linear model and M-M model, source plant was once again included as a random effect. We used Akaike's information criterion corrected for small sample size $\left(\mathrm{AIC}_{\mathrm{c}}\right)$ to compare models. We also compared linear and $\mathrm{M}-\mathrm{M}$ models for the full data set, including PCR-positive and PCRnegative insects, and for a data set including only PCR-positive insects. For the M-M models, we used initial parameter vales of $\mathrm{a}_{0}=8$ and $\mathrm{b}_{0}=4$. We assessed the fit of the M-M models by a linear regression between model-predicted and observed data for $X$. fastidiosa populations in vectors, using both the full data set and only PCR-positive individuals. Finally, we tested for independence between vector infection status and test plant infection status using a $\chi^{2}$ test with Yate's continuity correction. In all tests, $X$. fastidiosa population data were natural log transformed to meet model assumptions.

In the tests above-except for the $\chi^{2}$ test-we included source plant as a random effect. Because we used four source plants (AAP and IAP assays combined) out of logistical constraints, insects that acquired from the same source plant are not strictly independent; including source plant as a random effect allowed us to explicitly model this lack of independence. Our inclusion of source plant is analogous to a block effect in a randomized incomplete block design in that not all treatments were assigned to all source plants. To present the relationships between transmission and AAP, IAP, and $X$. fastidiosa populations in vectors, we estimated the modelpredicted or marginal probability of transmission from the model coefficients of the fixed effects in the model. The data are available as supplementary material (Supplementary Table S1). All analyses were run in R 3.2.1 ( $\mathrm{R}$ Core Team 2015). The mixed-effects logistic regression was fit using the lme4 package (Bates et al. 2014). The M-M mixed-effects model was fit using the nlme package (Pinheiro et al. 2014). $R$ code for running analysis and generating figures can be found at https://github.com/arzeilinger/xylella_philaenus_transmission.

\section{RESULTS}

Vector transmission efficiency. Transmission increased slightly yet significantly as AAP and IAP increased (Table 1). The proportions of test plants infected by $X$. fastidios $a$ at different AAP and IAP durations are shown in Figure 1. Based on AIC and logistic regression results, IAP and AAP had equivalent effects on transmission probability (Table 1; Fig. 1), with acquisition and inoculation efficiencies of approximately $15 \%$ per individual per day were observed. The $\mathrm{AIC}_{\mathrm{c}}$, which we used to compare different models, indicated that a single model relating AAP, IAP, and $X$. fastidiosa populations in vectors to transmission was better than AAP and IAP modeled separately $\left(\mathrm{AIC}_{\mathrm{AAP}}=170.5, \mathrm{AIC}_{\mathrm{IAP}}=168.2, \mathrm{AIC}_{\mathrm{AAP}+\mathrm{IAP}}=159\right.$; note, all three models included $X$. fastidios $a$ populations and source plant in addition to AAP, IAP, or both). Vector transmission to plants was significantly related to $X$. fastidiosa population size in vectors (Table 1; Fig. 2). Finally, the relationship between test plant infection status and spittlebug infection status was not strong, 15 of 44 PCR-positive insects and 16 of 192 PCR-negative individuals transmitted $X$. fastidiosa to plants, but the factors were not independent ( $\left.\mathrm{df}=1, \chi^{2}=18.62, P<0.0001\right)$.

Bacterial population in insects and relationship to time after beginning of AAP. The relationship between $X$. fastidiosa populations in vectors and time after the beginning of AAP until sample collection (AAP plus IAP) was not a significant linear relationship $(t=-0.245, P=0.806)$. At the same time, the relationship was better explained by the Michaelis-Menten model than the linear model (Fig. 3), whether including both PCR-positive and PCR-negative spittlebugs $\left(\mathrm{AIC}_{\text {linear }}=992.2, \mathrm{AIC}_{\mathrm{M}-\mathrm{M}}=986.8\right)$ or when including only PCR-positive individuals $\left(\mathrm{AIC}_{\text {linear }}=149.0\right.$, $\left.\mathrm{AIC}_{\mathrm{M}-\mathrm{M}}=147.9\right)$. The M-M model for the complete data set (PCRpositive and PCR-negative individuals) did not fit the data $\left(R^{2}<\right.$ $0.0001, P=0.907)$, but the data from only PCR-positive vectors fit moderately well $\left(R^{2}=0.399, P<0.0001\right)$.

Assessment of vetch as an $X$. fastidiosa host. One week after IAP, 16 of 31 vetch plants tested positive for X. fastidiosa. Over half of infected plants $(56.25 \%)$ hosted an X. fastidiosa population of $10^{3} \mathrm{CFU} / \mathrm{g}$, while the remaining $43.75 \%$ harbored $>10^{4} \mathrm{CFU} / \mathrm{g}$. Thus, vetch supports multiplication of $X$. fastidiosa as detected 1 week after the spittlebug IAP.

Philaenus spumarius natural infectivity. On 3 June, all grapevines $(n=10)$ tested in the field were negative for $X$. fastidiosa. However, 5 of the 10 monitored plants tested positive to $X$. fastidiosa on 18 June, hosting populations ranging from $10^{4}$ to $10^{7} \mathrm{CFU} / \mathrm{g}$. In July and August, 7 out of 10 plants were positive, with $X$. fastidiosa populations ranging from $10^{6}$ to $10^{8} \mathrm{CFU} / \mathrm{g}$. One of three test plants exposed to groups of five $P$. spumarius collected in August from weeds tested positive for the bacterium. Seven plants

TABLE 1. Statistical results for mixed-effects logistic regression of transmission, demonstrating that pathogen population in vectors, plant access period during acquisition and inoculation, as well as the intercept of all terms were significantly correlated with Xylella fastidiosa transmission to plants by Philaenus spumarius

\begin{tabular}{lcccc}
\hline Model term & Estimate & $\mathrm{SE}$ & $\mathrm{Z}$ & $P$ value $^{\mathrm{a}}$ \\
\hline Intercept & -6.23385 & 1.14085 & -5.464 & $4.65 \mathrm{E}-08^{* * * *}$ \\
$X$. fastidiosa population in & & & & \\
$\quad$ vector & 0.4374 & 0.09396 & 4.655 & $3.23 \mathrm{E}-06^{* * *}$ \\
Acquisition access period & 0.05426 & 0.01708 & 3.176 & $0.001495^{* *}$ \\
Inoculation access period & 0.06392 & 0.01827 & 3.499 & $0.000467 * * *$ \\
\hline
\end{tabular}

a $* *, P<0.01 ;$ and $* * *, P<0.001$. 
exposed to $P$. spumarius in June and July, with a total of 77 $P$. spumarius collected from both grapes and weeds, tested negative for the presence of $X$. fastidiosa.

\section{DISCUSSION}

This work provides additional information about $X$. fastidiosa transmission biology by Cercopoidea vector species. Severin (1950) showed that $P$. spumarius transmission of $X$. fastidiosa had a short or absent latent period, and that infectivity was retained for up to 76 days in adults. These observations are similar to those expected for the better-studied sharpshooter leafhoppers (Almeida and Purcell 2003b; Hill and Purcell 1995a; Purcell and Finlay 1979; Severin 1949). Results obtained here indicate that time on pathogen source as well as recipient plants were positively correlated to transmission efficiency. In other words, transmission efficiency increased with acquisition and IAPs, similarly to the sharpshooter Graphocephala atropunctata (Purcell and Finlay 1979). Transmission efficiency by $P$. spumarius from grapevine to grapevine reached approximately $15 \%$ per individual per day (when varying for both acquisition and IAPs). This value was lower than those observed for a previous study with $P$. spumarius that used only a single AAP-IAP combination (Purcell 1980), and for the leafhopper G. atropunctata (Purcell and Finlay 1979), whereas it was closer to that observed for another leafhopper, $H$. vitripennis (Almeida and Purcell 2003b). Variability in transmission efficiency among species on the same plant are well established for $X$. fastidiosa vectors (Redak et al. 2004); furthermore, feeding tissue preference on one plant may significantly impact transmission rates via plant-pathogen interactions, and such difference may also be determined by vector-plant interactions (Daugherty et al. 2010). In addition, $X$. fastidiosa populations in grapevines have been correlated with vector transmission efficiency (Hill and Purcell 1997). Because $P$. spumarius prefers green succulent tissues (Weaver and King 1954), green flush tissue was offered to insects for pathogen acquisition; bacterial populations in these tissues were estimated to be $\sim 10^{6} \mathrm{CFU} / \mathrm{g}$, which is sufficient for acquisition but below what is usually present in symptomatic plant tissue (Hill and Purcell 1995b). Therefore, it is also possible that transmission efficiency was relatively low because bacterial populations in source plant tissue were not high.

$X$. fastidiosa is persistent in adult cicadellid and aphrophorid vector species (Severin 1949, 1950). Nymphal stages loose infection at each molt because the bacterium is limited to the cuticular foregut lumen of insect hosts, which is shed at each life stage (Almeida and Purcell 2003b; Purcell and Finlay 1979). The bacterium colonizes the precibarium and cibarium of vectors (Brlansky et al. 1983; Cornara et al. 2016; Purcell et al. 1979), where it multiplies and forms a biofilm after initial attachment to the foregut surface (Almeida and Purcell 2006). Initial growth of the microcolony, as measured by quantitative PCR soon after bacterial acquisition from infected plants, has shown that $X$. fastidiosa multiplies exponentially with a doubling time of 7 to $8 \mathrm{~h}$ (Killiny and Almeida 2009b). For the best-studied vector species, $G$. atropunctata, bacterial populations in vectors usually reach $\sim 10^{5}$ cells/insect several days after acquisition, which has been reproduced in different studies (Killiny and Almeida 2009b; Rashed et al. 2011), and suggests that physical space available for colonization on the foregut is limited. Although colony growth could suggest that higher bacterial populations in vectors would lead to higher transmission efficiency, there is no evidence supporting this hypothesis. First, there is no detectable latent period required for $X$. fastidios $a$ transmission, indicating that few cells are sufficient for transmission (Purcell and Finlay 1979). The lack of a latent period also suggests that biofilm maturation is not required for $X$. fastidiosa inoculation. Efforts to correlate $X$. fastidiosa

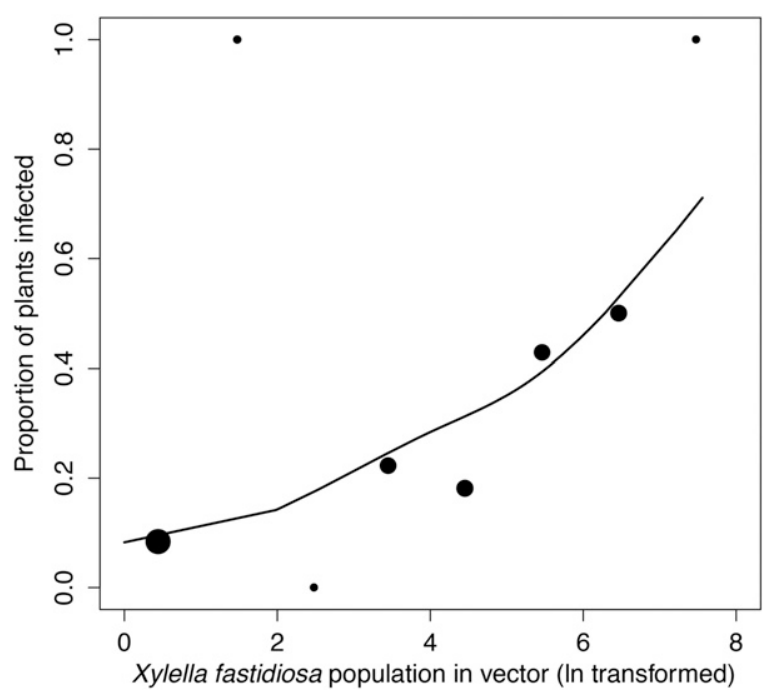

Fig. 2. Relationship between the modeled probability of Xylella fastidiosa transmission and populations of X. fastidiosa in Philaenus spumarius, for the entire data set (PCR-positive and PCR-negative vectors). Points indicate the proportion of test plants infected binned in intervals of 1 natural $\log$ of numbers of $X$. fastidiosa cells; points are placed at the median of intervals. The size of points represents their respective sample size: smallest points $1 \leq n<$ 10 , medium points $10 \leq n<100$, and largest point $n \geq 100$. X. fastidiosa populations were natural $\log$ transformed to meet assumptions of linear models.
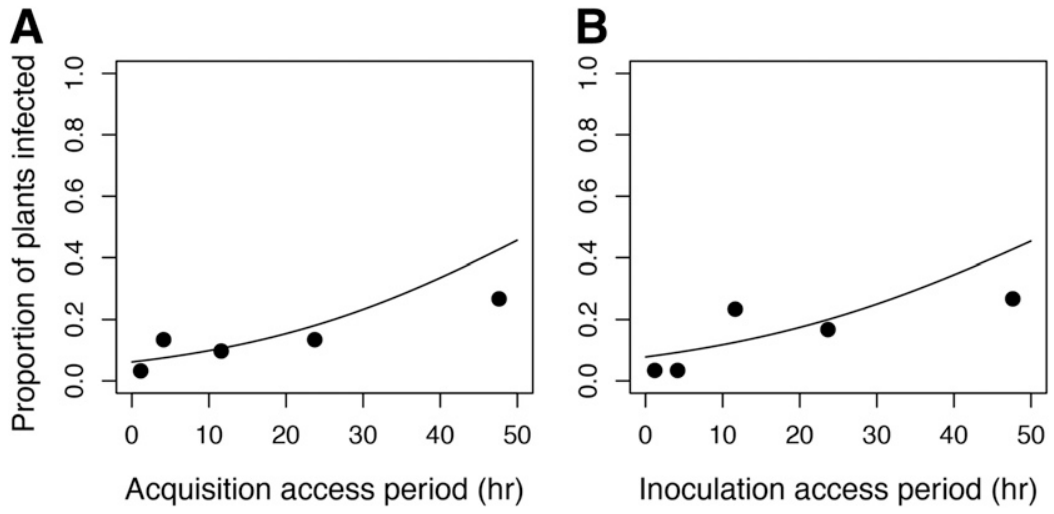

Fig. 1. Relationship between Xylella fastidiosa transmission and spittlebug pathogen $\mathbf{A}$, acquisition access period and $\mathbf{B}$, inoculation access period on plants. In both panels, the line indicates the model-predicted (marginal) probability of transmission, and the points indicate the proportion of test plants testing positive for $X$. fastidiosa at each time point. Sample size $n=30$ for each time point. 
populations in vectors with transmission to plants have suggested that, using the culturing method to estimate the number of cells in insect heads, there was no relationship between these two parameters (Almeida and Purcell 2003b; Hill and Purcell 1995a). The data set generated in this manuscript allowed questions on the role of bacterial populations in vectors in relation to transmission to be addressed.

First, a positive and significant relationship between $X$. fastidiosa populations in vectors and the proportion of plants infected was detected. In other words, larger bacterial populations in vectors were correlated with more transmission events. Although biofilm formation in vectors is a complex process (Killiny and Almeida 2009a, 2014), these results and the lack of a latent period for transmission suggest that cell detachment from the cuticle occurs at various stages of biofilm development. We propose that fluid dynamics in the mouthparts, where xylem-sap has been estimated to flow at $8 \mathrm{~cm} / \mathrm{s}$ (Purcell et al. 1979), driven by a piston-like pumping system with a frequency of one up-down movement per second (Dugravot et al. 2008), is a stronger determinant of $X$. fastidiosa inoculation than biofilm developmental stage. However, that hypothesis must be appropriately tested. Another observation is that a significant relationship between spittlebug and recipient plant infection status was found. One-third of positive insects, and less than $10 \%$ of negative individuals transmitted $X$. fastidios $a$ to plants. Although it is evident that the relationship is not strong, as previously suggested with work based on cell culturing instead of qPCR as a detection method (Almeida and Purcell 2003b; Hill and Purcell 1995a), it is possible that larger data sets and improved detection protocols may enhance the significance of the correlation. However, we emphasize the need for experimentally linking detection in vectors to transmission to plants. It is clear that there is still no reliable protocol for monitoring for the presence of $X$. fastidiosa in vectors and connecting those results to pathogen transmission risk.

The results also suggest that, for $P$. spumarius, there is a saturation point for the number of cells detected in the mouthparts, which is reached within days from $X$. fastidiosa acquisition. In addition, results indicate that population size may be limited to fewer than 1,000 cells. The number of cells estimated was from one to two orders of magnitude smaller than that found in sharpshooter

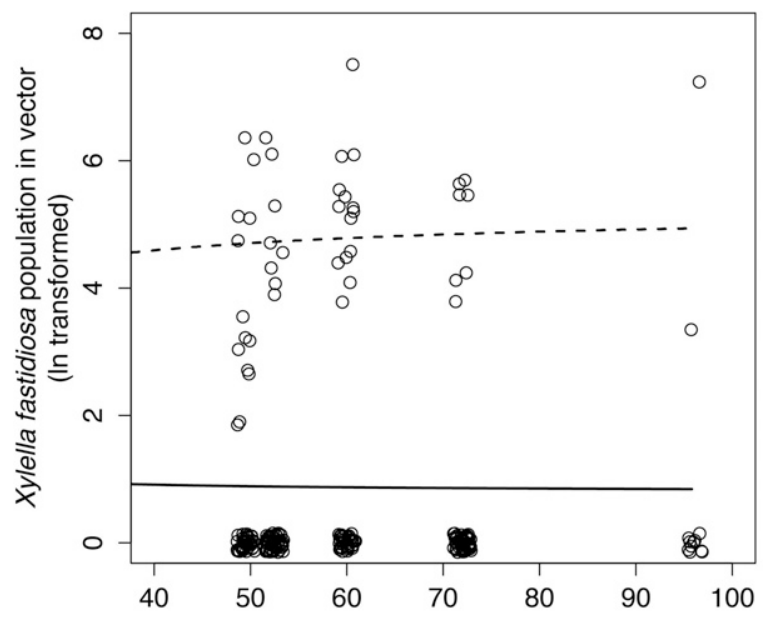

Time after beginning of aquisition access period (hr)

Fig. 3. Relationship between time after the beginning of the acquisition access period and population size of Xylella fastidiosa in Philaenus spumarius heads (natural $\log$ transformed). The relationship was explained by a MichaelisMenten model (shown here as fitted lines) better than by a linear model. Solid line represents model fit when including the entire data set (PCR-positive and PCR-negative vectors); dashed line represents model fit when only including PCR-positive vectors. A small amount of variation was included when plotting the data to indicate where multiple points had the exact same values. vectors (Retchless et al. 2014). Because $X$. fastidiosa is persistent in P. spumarius (Severin 1950), we assume that cells multiply in the foregut after initial adhesion. Following that scenario, we propose that the limited number of cells in the foregut of $P$. spumarius is either a consequence of fluid dynamics different from leafhoppers, leading to fewer cells attached overall, or limited cell population growth in this insect. It is possible that polysaccharides important for biofilm formation on the cuticle of $P$. spumarius are not as accessible for the bacterium as is the case for leafhoppers, which could lead to reduced cell growth. An alternative interpretation of the results is that cell number estimates by qPCR are not accurate. Because copies of the $X$. fastidiosa genome were correlated to colony forming units on plates, and this bacterium easily forms aggregates, it is possible that the number of cells as determined by qPCR is underestimated. However, this remark remains true for the estimation of the cell number in sharpshooters for which the same technique was used (Killiny and Almeida 2009b; Rashed et al. 2011). There may exist other technical limitations as well, but these factors would affect the number of cells, not the shape of the curve representing time after the beginning of the acquisition access period and $X$. fastidiosa populations in vectors. Altogether, we propose that $X$. fastidiosa populations in $P$. spumarius were limited in size due to physical constraint, which could be a combination of available surface space due to fluid dynamics and cuticle chemistry.

In summary, the transmission of $X$. fastidiosa by $P$. spumarius appears to follow expectations based on previous work done with sharpshooter leafhoppers. Transmission efficiency varies based on insect-plant-pathogen interactions, which are driven by the species or genotypes involved (Lopes et al. 2009), but results show that transmission increases with plant access time as expected. The relationships observed between bacterial populations in vectors and transmission to plants are novel and should be tested with other vector-pathogen-plant combinations. Finally, the role of spittlebugs on $X$. fastidiosa transmission has been largely ignored in the Americas, primarily due to the fact that sharpshooter leafhoppers appear to drive the main epidemics in the United States and Brazil (Redak et al. 2004). It is possible that spittlebugs are more important to pathogen spread in agricultural systems than previously thought. In addition, the role of these insects may be significant in the maintenance of $X$. fastidiosa in the environment. Furthermore, the introduction of $X$. fastidiosa in Europe has led to the identification of spittlebugs such as $P$. spumarius as species of particular interest in the region (Saponari et al. 2014). We expect that new research with this group of insects will generate information on $X$. fastidiosa transmission that should be applicable to various disease systems associated with this bacterium, as demonstrated in this study.

\section{ACKNOWLEDGMENTS}

We thank M. Lafler, D. Beal, J. Ezennia, and Y. Carrasco for assistance in laboratory activities. We also acknowledge C. Wistrom and the staff of UC Berkeley Greenhouse Facility Oxford tract for helping us in plant rearing. This work is part of D. Cornara's Ph.D. dissertation at the University of Bari, Italy. The research was funded by an award from the California Department of Food and Agriculture Pierce's Disease Research Program, and POnTE Horizon 2020.

\section{LITERATURE CITED}

Almeida, R. P. P., and Nunney, L. 2015. How do plant diseases caused by Xylella fastidiosa emerge? Plant Dis. 99:1457-1467.

Almeida, R. P. P., and Purcell, A. H. 2003a. Biological traits of Xylella fastidiosa strains from grapes and almonds. Appl. Environ. Microbiol. 69: 7447-7452.

Almeida, R. P. P., and Purcell, A. H. 2003b. Transmission of Xylella fastidiosa to grapevines by Homalodisca coagulata (Hemiptera: Cicadellidae). J. Econ. Entomol. 96:264-271.

Almeida, R. P. P., and Purcell, A. H. 2006. Patterns of Xylella fastidiosa colonization on the precibarium of sharpshooter vectors relative to transmission to plants. Ann. Entomol. Soc. Am. 99:884-890. 
Bates, D., Mächler, M., Bolker, B., and Walker, S. 2014. Fitting linear mixedeffects models using lme4. arXiv:1406.5823.

Brlansky, R. H., Timmer, L. W., French, W. J., and McCoy, R. E. 1983. Colonization of the sharpshooter vector, Oncometopia nigricans and Homalodisca coagulata by xylem-limited bacteria. Phytopathology 73:530-535.

Chatterjee, S., Almeida, R. P. P., and Lindow, S. 2008. Living in two worlds: the plant and insect lifestyles of Xylella fastidiosa. Phytopathology 46: 243-271.

Cornara, D., Saponari, M., Zeilinger, A. R., de Stradis, A., Boscia, D., Loconsole, G., Bosco, D., Martelli, G. P., Almeida, R. P. P., and Porcelli, F. 2016. Spittlebugs as vectors of Xylella fastidiosa in olive orchards in Italy. J. Pest Sci. doi: 10.1007/s10340-016-0793-0.

Daugherty, M. P., Bosco, D., and Almeida, R. P. P. 2009. Temperature mediates vector transmission efficiency: Inoculum supply and plant infection dynamics. Ann. Appl. Biol. 155:361-369.

Daugherty, M. P., Lopes, J., and Almeida, R. P. P. 2010. Vector within-host feeding preference mediates transmission of a heterogeneously distributed pathogen. Ecol. Entomol. 35:360-366.

Dugravot, S., Backus, E. A., Reardon, B. J., and Miller, T. A. 2008. Correlations of cibarial muscle activities of Homalodisca spp. sharpshooters (Hemiptera: Cicadellidae) with EPG ingestion waveform and excretion. J. Insect Physiol. 54: 1467-1478.

Eden-Green, S., Balfas, R., and Sutarjo, T. 1992. Characteristics of the transmission of Sumatra disease of cloves by tube-building cercopoids, Hindola spp. Plant Pathol. 41:702-712.

Feil, H., and Purcell, A. H. 2001. Temperature-dependent growth and survival of Xylella fastidiosa in vitro and in potted grapevines. Plant Dis. 85: 1230-1234.

Francis, M., Lin, H., Cabrera-La Rosa, J., Doddapaneni, H., and Civerolo, E. L. 2006. Genome-based PCR primers for specific and sensitive detection and quantification of Xylella fastidiosa. Eur. J. Plant Pathol. 115:203-213.

Frazier, N. W. 1965. Xylem viruses and their insect vectors. Pages 91-99 in: Proceedings of the International Conference on Virus and Vectors on Perennial Hosts, with Special Reference to Vitis.

Frazier, N. W., and Freitag, J. H. 1946. Ten additional leafhopper vectors of the virus causing Pierce's disease of grapes. Phytopathology 36:634-637.

Freitag, J. H. 1951. Host range of the Pierce's disease virus of grapes as determined by insect transmission. Phytopathology 41:920-934.

Hewitt, W. B., Frazier, N. W., Jacob, H. E., and Freitag, J. H. 1942. Pierce's disease of grapevines. Calif. Agric. Exp. Stn. Circ. 1-32.

Hewitt, W. B., and Houston, B. R. 1946. Leafhopper transmission of the virus causing Pierce's disease of grape and dwarf of alfalfa. Phytopathology 36: 117-128.

Hill, B. L., and Purcell, A. H. 1995a. Acquisition and retention of Xylella fastidiosa by an efficient vector, Graphocephala atropunctata. Phytopathology 85:209-212.

Hill, B. L., and Purcell, A. H. 1995b. Multiplication and movement of Xylella fastidiosa within grapevine and four other plants. Phytopathology 85: 1368-1372.

Hill, B. L., and Purcell, A. H. 1997. Populations of Xylella fastidiosa in plants required for transmission by an efficient vector. Phytopathology 87:1197-1201.

Killiny, N., and Almeida, R. P. P. 2009a. Host structural carbohydrate induces vector transmission of a bacterial plant pathogen. Proc. Natl. Acad. Sci. USA 106:22416-22420.

Killiny, N., and Almeida, R. P. P. 2009b. Xylella fastidiosa afimbrial adhesins mediate cell transmission to plants by leafhopper vectors. Appl. Environ. Microbiol. 75:521-528.

Killiny, N., and Almeida, R. P. P. 2014. Factors affecting the initial adhesion and retention of the plant pathogen Xylella fastidiosa in the foregut of an insect vector. Appl. Environ. Microbiol. 80:420-426.
Krell, R. K., Boyd, E. A., Nay, J. E., Park, Y.-L., and Perring, T. M. 2007. Mechanical and Insect Transmission of Xylella fastidiosa to Vitis vinifera. Am. J. Enol. Vitic. 58:211-216.

Lopes, J. R., Daugherty, M. P., and Almeida, R. P. P. 2009. Context-dependent transmission of a generalist plant pathogen: Host species and pathogen strain mediate insect vector competence. Entomol. Exp. Appl. 131:216-224.

Ossiannilsson, F. 1981. The Auchenorrhyncha (Homoptera) of Fennoscandia and Denmark. Part 2: The families Cicadidae, Cercopidae, Membracidae, and Cicadellidae (excl. Deltocephalinae). Fauna Entomologica Scand. 7: 223-593.

Paião, F. G., Meneguim, A. M., Casagrande, E. C., and Leite, R. P. 2002. Envolvimento de cigarras (Homoptera, Cicadidae) na transmissão de Xylella fastidiosa em cafeeiro. Fitopatol. Bras. 27:67.

Pinheiro, J., Bates, D., DebRoy, S., and Sarkar, D. 2014. nlme: Linear and nonlinear mixed effects models. R package version 3.1-117. Available at https://cran.r-project.org/web/packages/nlme/index.html

Purcell, A. H. 1980. Almond leaf scorch: Leafhopper and spittlebug vectors. J. Econ. Entomol. 73:834-838.

Purcell, A. H. 1981. Vector preference and inoculation efficiency as components of resistance to Pierce's disease in European grape cultivars. Phytopathology 71:429-435.

Purcell, A. H., and Finlay, A. H. 1979. Evidence for non-circulative transmission of Pierce's disease bacterium by sharpshooter leafhoppers. Phytopathology 69:393-395.

Purcell, A. H., Finlay, A. H., and McLean, D. L. 1979. Pierce's disease bacterium: Mechanism of transmission by leafhopper vectors. Science 206: 839-841.

R Core Team. 2015. R: A language and environment for statistical computing. Vienna, Austria. http://www.R-project.org

Rashed, A., Killiny, N., Kwan, J., and Almeida, R. P. P. 2011. Background matching behavior and pathogen acquisition: plant site preference does not predict the bacterial acquisition efficiency of vectors. Arthropod-Plant Interact. 5:97-106

Redak, R. A., Purcell, A. H., Lopes, J. R., Blua, M. J., Mizell, R. F., III, and Andersen, P. C. 2004. The biology of xylem fluid-feeding insect vectors of Xylella fastidiosa and their relation to disease epidemiology. Annu. Rev. Entomol. 49:243-270.

Retchless, A. C., Labroussaa, F., Shapiro, L., Stenger, D. C., Lindow, S. E., and Almeida, R. P. P. 2014. Genomic insights into Xylella fastidiosa interactions with plant and insect hosts. Pages 177-202 in: Genomics of PlantAssociated Bacteria. Springer, New York.

Sanderlin, R. S., and Melanson, R. A. 2010. Insect transmission of Xylella fastidiosa to pecan. Plant Dis. 94:465-470.

Saponari, M., Loconsole, G., Cornara, D., Yokomi, R. K., De Stradis, A., Boscia, D., Bosco, D., Martelli, G. P., Krugner, R., and Porcelli, F. 2014. Infectivity and transmission of Xylella fastidiosa by Philaenus spumarius (Hemiptera: Aphrophoridae) in Apulia, Italy. J. Econ. Entomol. 107: 1316-1319.

Severin, H. 1949. Transmission of the virus of Pierce's disease of grapevines by leafhoppers. Hilgardia 19:190-206.

Severin, H. 1950. Spittle-insect vectors of Pierce's disease virus. II. Life history and virus transmission. Hilgardia 19:357-382.

Weaver, C. R., and King, D. R. 1954. Meadow spittlebug. Ohio Agric. Exp. Stat. Res. Bull. 741:1-99.

Yurtsever, S. 2000. On the polymorphic meadow spittlebug, Philaenus spumarius (L.) (Homoptera: Cercopidae). Turk. J. Zool. 24:447-460.

Zeilinger, A. R., and Daugherty, M. P. 2014. Vector preference and host defense against infection interact to determine disease dynamics. Oikos 123: 613-622. 